\title{
Study on the Industrial Ecological Compensation in Inter-basin
}

\author{
Regions \\ Yachen Liu \\ School of Management, Shenyang Jianzhu University, Shenyang 110168, China \\ Tel: 86-24-24692208Ｅ-mail: lyc@sjzu.edu.cn
}

The research is financed by the "Total Project of the Water Pollution Control in Liaohe River Drainage Basin" of the National Science and Technology Key Project of "Control and Treatment of Water Pollution" (No. 2008ZX07208-001). (Sponsoring information)

\begin{abstract}
Aiming at the inter-basin pollution of water sources, the meaning, the content, and the system of the industrial ecological compensation are proposed in this article and the corresponding inter-basin industrial ecological compensation institution is suggested to be established.
\end{abstract}

Keywords: Inter-basin, Industry, Ecological compensation

\section{Meanings of Inter-basin Industrial Ecological Compensation}

1.1 To establish the industrial ecological compensation mechanism is the important part to perfect the ecological compensation mechanism

It is the requirement for the human society to implement the complete, harmonious, and sustainable scientific outlook on development, and to establish the environment-friendly society, and to realize the harmonious development between human and nature for higher level and higher stage, and it is the urgent important task. The healthy and complete ecological compensation mechanism could offer system and mechanism guarantee for the construction of the environment-friendly society. At present, according to different standards, the methods and approaches of the ecological compensation mechanism of China can be classified differently. And the compensation modes include the capital compensation, the material compensation, the policy compensation, and the intelligent compensation. According to the compensation regions, the compensation can be divided into the vertical compensation and the transverse compensation. According to the space size, the compensation could be divided into the ecological environment factor compensation, the drainage basin compensation, the region compensation, and the international compensation ( $\mathrm{Li}, 2007)$. But their essential is the result of the extensive growth of the economy and industry in China, so to solve the sources of the ecological environment problems at all, the new ecological compensation mechanism should be established from the view of industry.

1.2 The industrial ecological compensation mechanism is the effective approach to reduce the pressure of the environment development

At present, China is facing the new development opportunity, and many heavy and chemical industries need to be developed. These products are not only necessary for the economic construction, but also belong to the industries with high energy consumption and heavy pollution. This stage is the term that the environment pressure is most heavy, so the establishment of the industrial ecological compensation mechanism could effectively control the discharge of wastes and reduce the pressure of the environment.

1.3 To establish the industrial ecological compensation mechanism is the guarantee to realize the internalization of the exterior cost of the environment for the enterprise

The ecological compensation mechanism is the effective method to define the environment property right and the environment production factors, which could internalize the exterior environment cost of the production activities of the enterprise, and be the effective economic measure to promote the enterprise to protect the environment and assume the treatment tasks. 
1.4 To establish the industrial ecological compensation mechanism is the effective mode to adjust the relationship of the environment benefit

The establishment of the industrial ecological compensation mechanism could not only treat the relation between environment and economy, but also make for the adjustment of the harmonious relation of the society, and drive the technical updating of other industries, enhance the employment rate and the talent cultivation, promote the regional economic mutual support, and offer system guarantee to adjust the development among economy, society, and environment.

\section{Content of the Inter-basin Industrial Ecological Compensation}

\subsection{Main body of industrial ecological compensation}

The main body of the industrial economical compensation mechanism should include the compensating body and the compensated body of various unit ecological compensations, and they are respectively the right body and the obligation body of the ecological compensation mechanism in the basin.

Because the inter-basin ecological function has the characteristic of commonweal, the compensated body must represent the public benefit. And because numerous units or individuals benefit form the inter-basin ecological function, so it is very difficult to harmonize and complete the capture of the compensation charge, and only the government could assume this responsibility to harmonize and capture the compensations. Therefore, the beneficiaries of the inter-basin ecological benefit should pay the compensation charges for the government, i.e. pay the inter-basin ecological compensations (Feng, 2009, P.85-89).

The obligation body is the destroyer of the inter-basin ecological environment, and includes enterprises and individuals.

\subsection{Industrial ecological compensation modes}

\subsubsection{Mode of government compensation}

The government compensation means the compensation mode that the country or the upper government takes the regional government as the compensation object and takes the regional harmonious development as the target. And it gives priority to the payment of financial transfer, and the enterprise taxation is the important source.

\subsubsection{Mode of market compensation}

It is the regional compensation by the relationship of the industry chain and the value chain. By the market trade or payment, the value of the ecological (environment) service function and the marketization mode of optimizing and allocating the inter-basin resources are realized. This mode takes the Coase Theorem as references to implement the independent trade in the market based on clear property rights.

\subsubsection{Mode of benefit compensation}

Aiming at different economic development actualities in the basin, considering general demand of economic development, the benefit compensation mode mainly includes the support mode and the economic cooperation mode. And the economic operation mode is the optimal selection of the benefit compensation mode. In the region full of mine resources, the dominant industries of many administrative units are the mental or non-mental mining and processing industries. The mining and processing industries could produce water loss and soil erosion and destroy the water source. The development will of these regions is strong, so it is not practical to forbid the resource development in these regions, but only instruct and support them to develop the substitute industries, and cultivate new growth points of the local economy according to local conditions, and enhance the industrial compensation of the upper regions, and gradually optimize the regional economic structure, and encourage the enterprises benefiting in the region to develop the environment protection business in the weak ecological regions.

\subsubsection{Developing relative financial industries actively}

The government should also strengthen the association with the financial departments, and seek relative experts' help and technical supports, and establish the funds to seek and donation and supports from foreign non-governmental organizations, and issue the welfare lotteries to promote the participation of the whole society. All above measures could be adopted to promote the multi-development of the multi-financial industries.

\section{Inter-basin Industrial Ecological Compensation Management Institution}

\subsection{Main functions}

\subsubsection{Integrating and transferring inter-basin resources}

The environment factor market should be cultivated, and the paid distribution mechanism of the pollution discharge index in the region should be established as soon as possible. The pollution discharge right trade under the control of government should be pushed gradually. The economic structure should be adjusted and optimized to develop the substitute industry and the special industries, push the clean production largely, develop the circle economy, drive the 
industry transfer in the regions and the reasonable flow of factors, and promote the essential change of the ecological environment.

\subsubsection{Exploring the standards of inter-basin industrial ecological compensation}

The government should attempt to take the inter-basin resources as the prices of the production factors and the living factors, and start from the actual development of the basin to establish the standard of the inter-basin industrial ecological compensation, and gradually realize the scientific and standard market compensation mode. Taking the water source as the example, using the trans-state water right trade in west countries as the reference, Yiwu and Dongyang in Zhejiang adopted the market mechanism and realized the ecological compensation in the basin. After that, Shaoxing and Cixing also established the relation of the water source trade.

\subsubsection{Establishing the cooperation mechanism of industrial ecological compensation}

As viewed from the industrial development and diffusion, the inter-basin regional cooperation mechanism could harmonize the benefit relations among units, and complete the industrial ecological compensation layer by layer and stage by stage, and realize the real harmony among economy, society, and environment.

\subsubsection{Establishing multiform and multi-channel financing mechanisms}

The social and civil capitals should be encouraged to invest in the domain of ecological environment protection and treatment, and the threshold should be reduced, and the industrial monopoly should be broken, and the market admittance of the environment protection infrastructure should be opened.

The various current taxation policies protecting the environment should be perfected to offer financial guarantee for the establishment of the ecological compensation mechanism.

The administrative charge range should be extended, and the main pollute discharge enterprises should be supervised on line, and collect pollution discharge fees for those enterprises exceeding the discharge standards. The government should issue the policies that the beneficial regions offer economic compensation for the environment protection region, or the enterprises inducing the pollution accident offer compensation for the polluted region.

The government should also establish the special capital of the ecological environment construction, and list it into the financial budget of the government, strengthen the prevention and control of the regional and basin pollution, and largely support the new technology and application about the pollution control. At the same time, various governments should fully utilize multiple channels such as the government discount, investment assistance, and pollution charge to attract the social capitals to invest the ecological environment. The preferential benefit and the donation mechanism of the environment protection should be established, and the national debt capitals, the development credit and the loans or endows of international organizations and foreign governments should be actively utilized to form the multiple financial channels.

The caution money system should be established. The enterprises polluting or destroying the environment should establish the environment governance plans and concrete measures, and pick up certain proportion of the sales incomes of mineral products to be the environment caution money.

\subsection{Composing}

The Inter-basin industrial ecological compensation management institution is composed by various unit governments, relative management departments, non-government institutions, and experts in the inter-basin space, and it should establish the linkage mechanism with the highest administrative government in the basin (such as the provincial government) to implement the decision-making right, the execution right, and the supervision rights of the industrial ecological compensation in the basin.

\section{References}

Feng, Yanfen., Liu, Yihua \& Wang, Fang. (2009). Progress of Ecological Compensation Practice in China. Ecological Economy. No.8. P.85-89.

Li, Qun. (2007). Study on the Ecology Compensation Mechanism of the Water Source Protection Zone of Dongjiang Drainage Area. Lanzhou: Mater's Degree Thesis of Northwest University for Nationalities.

WU, Yuyan \& Zhang, Keyun. (2009). Study on the Regional Cooperation Mechanism Inter-District Drainage Area. Lanzhou Academic Journal, No.5. P.69-73. 